\title{
War for Territory. cenas musicais, experiência estética e uma canção heavy metal
}

\author{
Jeder Silveira Janotti Junior
}

\section{Resumo}

Esse artigo aborda as cenas musicais como territórios sonoros onde se materializam os gêneros musicais, tendo como estudo de caso a configuração do heavy metal em seus traços genéricos e no modo como essas marcas são singularizadas na canção Territory do grupo mineiro Sepultura. Esse exercício analítico nos permite observar em que medida a sonoridade funciona como ponto de partida para a articulação de experiências estéticas que permeiam a configuração local e global das cenas musicais.

\section{Palavras-Chave}

Cena Musical. Experiência Estética. Heavy Metal.

Jeder Silveira Janotti Junior I jederj@gmail.com Doutor em Ciências da Comunicação pela Universidade do Vale do Rio dos Sinos (2002), com estágio de doutoramento na McGill University (Montreal, 2000). Atualmente é professor da Universidade Federal de Pernambuco.

\section{Do que, afinal, estamos falando?}

Há Nos últimos anos, é possível observar uma dissociação velada entre os estudos que procuram abordar a música como um fenômeno social-econômico e a busca da compreensão das expressões musicais contemporâneas em seus aspectos estéticos. Esse artigo parte da proposição de uma inter-relação entre essas perspectivas, argumentando que os aspectos sensíveis do consumo musical não estariam dissociados de sua materialização em produtos das indústrias culturais. Para aprofundar os diálogos críticos que envolvem 0 encontro entre os estudos culturais e a estética da comunicação procurei tecer essa jornada em dois momentos que funcionam como uma interface:

1) a busca por uma sistematização das experiências que marcam a existência das cenas musicais na cultura contemporânea, sua articulação com os gêneros musicais e com a singularidade dos consumos musicais em seus processos de midiatização; 
2) a materialização dessas discussões na configuração do gênero musical heavy metal e como essas questões emergem na canção Territory da banda brasileira Sepultura.

Dentro dessa perspectiva, consumir música é um processo que conecta uma rede cultural formada por usuários que baixam arquivos na internet, fãs que consomem música ao vivo, críticos culturais, jovens que se iniciam nas práticas de instrumentos musicais, músicos, técnicos de som, produtores culturais e amigos que se reúnem para conversar sobre suas bandas e álbuns favoritos. Enfim, todas essas práticas e aprendizados corroboram a ideia de que a música é um dos produtos culturais mais significativos de nosso tempo e que para se compreender esse processo é necessário encarála tanto como um circuito cultural quanto como um ambiente comunicacional.

Segundo Herschman (2007) circuitos culturais são espaços urbanos marcados geograficamente (locais de shows, lojas de instrumentos musicais, bares, teatros, pontos de encontro etc.) ou simbolicamente (festivais, interações digitais etc.) que agrupam lógicas comerciais a processos culturais e experiências estéticas. Desde já, é importante perceber que a experiência em presença da música neste universo não é vista como algo destacado das práticas sociais. Pelo contrário, tal como afirma o pesquisador Harris Berger (1999, p. 23, tradução nossa, grifo nosso), ao estudar a cena musical de death metal ${ }^{1} \mathrm{em}$ Akron nos Estados Unidos:

Aqui, 0 objeto de estudo é a experiência particular de uma pessoa que escuta os aspectos formais e afetivos da canção, o movimento dos músicos no palco, o moshing do público, o gosto da cerveja e de qualquer outro elemento do evento que o participante agarra concretamente. A constituição dessas experiências do participante é influenciada pelas intenções dela ou dele em freqüentar 0 evento (o desejo de sair de casa, de ouvir música complexa e furiosa, de apoiar a cena local) e suas habilidades de percepção (habilidades de escuta, conhecimento da interação de estilos em um show de metal). Estas, por sua vez, são configuradas pela experiência musical passada (anos de escuta de metal, um interesse no punk hardcore, aulas de música no colégio) e experiências não-musicais (um dia legal de trabalho, ideias locais sobre gêneros, um grupo de trabalhadores não sindicalizados em, empregos no setor de serviços)².

É importante observar que a afirmação das cenas musicais ocorre através de experiências que são nomeadas (e modeladas) pelos modos como crítica, músicos e público definem essas experiências. Desse modo, compreende-se 0 alcance de uma cena e suas conexões sonoras, através de suas perspectivas regionais (cena indie carioca), suas

Death Metal é um subgênero do heavy metal surgido em meados dos anos 1980.Entre as principais características do subgênero destacam-se as temáticas mórbidas das letras, os vocais agressivos, variações rítmicas que englobam rapidez e cadenciamento, utilização extrema das distorções de guitarra. A primeira geração de bandas tinha como destaque Kreator, Sepultura, Death e Morbid Angel. Hoje, o Death Metal segue uma série de variações como Death Doom, Death Metal Melódico e Death Metal Progressivo. 
ligações nacionais (cena punk brasileira) e suas conexões globais (cena heavy metal).

Nessa direção, a articulação entre julgamentos de valor e o papel autorreflexivo da nomeação das cenas servem de base para 0 reconhecimento de experiências estéticas atreladas a gêneros musicais e sua conformação nos tecidos urbanos. 0 ambiente comunicacional da música popular massiva envolve processos de midiatização em seus aspectos sensíveis, sociais, tecnológicos e econômicos, conectando cidades a redes virtuais, shows a escutas individualizadas, consumo coletivo à produção privada de música.

Como podemos esperar, esse excesso de perguntas que se apóiam na mediatização ${ }^{3}$ não tornou fácil a formulação de raciocínios sustentados e equilibrados; normalmente procedemos através de oposições: antes/depois, tradicional/ moderno, material/imaterial, real/virtual, presencial à distância, direcional/interativo, mono-mediático/multi-mediático, molar/molecular, centralizado/descentralizado, etc. E essas oposições perduram, mesmo se as dúvidas começarem a se manifestar quanto à possibilidade de uma substituição de um modo de comunicação (plurimilenar, vale lembrar) por outro. É porque, em oposição às visões substitutivas ou substitutas, que são a princípio oposições ante- riores, nos perguntamos se a perspectiva mais provável não é aquela da junção de novas modalidades orientadas em direção à mediatização a um modo de comunicação que se mantém, no essencial, além da diversidade das formas nas quais se revela para nós, de um lado a outro do planeta (MIÉGE, 2009, p. 82).

Nesse cenário, se antes, grande parte de experiências e lógicas de consumo estavam conectado aos lançamentos dos discos, hoje as análises valorativas também estão atreladas à importância do consumo da música ao vivo e ao funcionamento da crítica musical como prospector das cenas musicais emergentes.

Os julgamentos de valor em torno dos produtos editoriais como CDs e DVDs já não pressupõem um hiato entre a leitura da crítica e a aquisição do produto. Levando-se em conta a instantaneidade da circulação de músicas na internet, pode-se inferir que em boa parte dos casos, leitores e leitoras ou já conhecem os produtos criticados ou estão a apenas um clique do acesso a esses produtos. ${ }^{4} \mathrm{~A}$ crítica é um produto que afirma-se através de "comunidades de gosto" ao mesmo tempo em que serve como forma de divulgação do produto musical.

"Here, the study object is a particular listener's experience of the formal and affective aspects of the song, the stage moves of the musicians, the moshing of the crowd, the taste of the beer, and any other elements of the event that the participant concretely grasps. The participant's constitution of these experiences is influenced by his or her purposes in attending the event ( the desire to get out of the house, to hear intricate and furious music, to support the local music scene) and his or her perceptual skills (listening skills, knowledge of international style in metal shows). These, in turn, are informed by past musical experience (years of listening to metal, an interesting in hardcore punk, music classes in high school) ans nonmusical experiences ( a good day at work, local ideas about gender, a series of nonunion, service-sector jobs)."

Mantemos a grafia mediatização utilizada na citação para preservar a tradução da edição brasileira, ao longo do texto optamos pelo aportuguesamento midiatização de ampla utilização no mundo acadêmico brasileiro. 
É possível compreender um pouco mais da música como fenômeno comunicacional quando se passa a pensá-la de modo mais abrangente, localizando a importância da experiência estética e dos processos de midiatização para 0 entendimento da presença da música em nosso cotidiano.

Todos nós ouvimos a música que gostamos como algo especial, como algo que desafia 0 mundano, que nos leva para 'fora de nós mesmos', coloca-nos em algum outro lugar. 'Nossa música'5 é, dessa perspectiva, especial não só em relação a outras músicas, mas também, e mais importante, para o resto de nossas vidas (FRITH, 1996, p. 275, tradução nossa).

\section{Cenas, crítica e rotulações musicais}

Em geral, a relação de ouvintes dedicados envolve repetição e uma relação interacional entre escutas públicas (shows, bares), privadas (em casa, nos MP3 players, no carro), bem como funções de uso (música para dançar, música para cantar junto, música de fundo). Esses fatos corroboram a ideia de que mais do que "consumir" música, valoriza-se a experiência como lugar privilegiado da fruição musical,

[...] a 'experiência' exige a mobilização sensorial e fisiológica do corpo humano; é ao mesmo tempo uma atividade prática, intelectual e emocional; é um ato de percepção e, portanto, envolve interpretação, repertório, padrões: existe sempre em função de um 'objeto', cuja materialidade, condições de aparição e de circunscrição histórica e social não são indiferentes (GUIMARÃES; LEAL, 2007, p. 7).

Dentro dessa perspectiva, busca-se aliar a importância dada aos processos de digitalização que transformaram 0 acesso e a produção musical à presença maciça da música ao vivo nas cidades contemporâneas,

Diferentemente da grande indústria, os músicos já não parecem se opor a que a pirataria e as trocas de arquivos sejam intensamente praticadas. Apesar de a maioria não apoiar abertamente livre circulação de fonogramas, parece haver uma consciência mais ou menos clara não só de que a rede é fundamental para a formação e renovação de seu público, mas também de que seus ganhos advirão principalmente da comercialização da música executada ao vivo (HERSCHMANN, 2010, p. 64).

Além do aspecto econômico, é interessante observar que a valorização do consumo de músico ao vivo também está relacionada a transformações tecnológicas que agregaram valor a qualidade sonora da música ao vivo. Hoje, não é difícil encontrar boas sonorizações em shows de pequeno porte, onde equalizadores, processadores, potências e mesas de som

As grandes maiorias das críticas publicadas na internet apresentam links para os produtos criticados serem consumidos no Youtube ou para endereços que possibilitem os downloads das músicas.

"We all hear the music we like as something special, as something that defies the mundane, take us "out of ourselves", puts us somewhere else. "Our music" is, from this perspective, special not just with reference to other music but, more important, to the rest of life." 
proporcionam experiências diferenciadas em meio à algazarra das cidades contemporâneas. ${ }^{6}$

Invertendo então as abordagens tradicionais dos processos de comunicação que na maioria dos casos parte da definição dos conceitos, poderíamos começar perguntando: 0 que une diferentes utilizações do rótulo cena? Que emaranhado é esse que envolve experiências que se sobrepõe em camadas possibilitando 0 reconhecimento do valor desse rótulo em diferentes contextos do consumo musical?

Como se pode perceber no trecho da entrevista que o músico Wado concedeu ao site Scream and Yell, cena musical designa, em primeiro lugar, um território sonoro que envolve um processo de midiatização do consumo musical em determinado espaço geográfico:

A gente tem tocado bastante, mas todo mundo tem outras bandas, ou trabalha com outras coisas. Tem uma renovação de cena. Acho que vem ai uma nova safra de discos de Alagoas bem boa. 0 Mopho está gravando com uma qualidade bem legal, com a banda quase no formato original. Tem a Cris Braun que está terminando o disco e está massa. 0 Xique Baratinho também está gravando disco. Tem o Vitor Piralho, que também foi premiado com o Projeto Pixinguinha. Acho que ele é um dos principais da nova safra (COSTA, 2012, grifo nosso).

Wado está falando de músicos alagoanos que fazem parte do circuito musical de Maceió, o que traz implicações sobre o modo como se articulam identidades regionais, experiências singulares e o mercado de música. ${ }^{7}$ Mas, o que parece mais interessante neste uso é que, ao invés de referenciar-se a partir de um gênero musical (cena carioca de samba ou cena paulista de heavy metal), é relevante a ideia de cena musical como um conjunto de práticas musicais singulares. ${ }^{8}$ A título de exemplo, pode-se perceber como a matéria "Doçura Psicodélica", congrega feitios estéticos em torno das especificidades sonoras e regionais da banda Box Lunar,

Fala-se muito do barateamento da produção e dos aparelhos de reprodução de música gravada mas também deve-se observar que essa acessibilidade também transformou a qualidade e a presença da música ao vivo em nosso cotidiano.

Uma outra inferência possível quando se utiliza a nomenclatura de um estado quando se está fazendo referência a cenas musicais que se materializam nas capitais é a incipiência ou mesmo a inexistência desses circuitos culturais no interior do estado. Por outro lado, é possivel imaginar que quando se utiliza demarcações específicas de uma grande cidade, como a cena rock de Los Angeles, está se reconhecendo a potência dos circuitos culturais dessas cidades.

Em termos de gêneros musicais as referências usadas por Wado (Nova MPB) são bem diversificadas: Mopho (rock setentista), Cris Braun (ex-vocalista da banda de Brock Sex Beatles, atualmente próxima da MPB), Xique Baratinho (próximo aos hibridismos que caracterizaram grande parte do rock produzido nos anos 1990 em que o destaque foi a cena Mangue de Recife) e Vitor Piralho (Rap). De modo geral esses são rótulos ou gêneros musicais de nicho que se diferenciam das correntes principais da música pop, como 0 sertanejo e o pop transnacional, não só na sonoridade e na produção como na amplitude da divulgação e da circulação dos produtos musicais. 
Na verdade, Macapá possui uma cena pequena, em que todos se conhecem - 0 tecladista 0tto e 0 baterista Taiguara tocam uma dezena de bandas locais ("mini Box" é o nome local para designar mercadinhos de bairro). Nessa terra ilhada cheia de gente que vem de longe (JJ é de Salvador, Alexandre de Brasília, Taiguara e Sandy de Belém, 0tto do interior do Pará - só Heluana nasceu no Amapá), a lenta destilação de rock e MPB resultou em uma doçura psicodélica e tipicamente amazônica (ANTUNES, 2009, grifo nosso).

Levando-se em conta essas implicações é possível reconfigurar a importância da circulação dos produtos culturais para a constituição das cenas. De acordo com Braga (2006, p. 28) "Importa que várias pessoas, tendo lido 0 mesmo livro ou ouvido e apreciado um mesmo tipo de música e tendo alguma informação sobre tais materiais, 'conversem `sobre tais objeto e interajam com base nesse estímulo". Podemos pensar que conversa aqui seja ampliada literalmente para a circulação de competências comunicacionais, ou seja, um sistema interacional de repostas diferidas e difusas que envolve circulação de sensibilidades, relações sociais, práticas mercadológicas e utilização de dispositivos sociotécnicos.

Assim, uma mesma experiência sonora pode atravessar rotulações de cena que ora privilegiam "territórios sonoros" localizados, ora privilegiam a circulação de práticas sonoras para além de seus lugares de origem. Mesmo que algumas cenas tenham moldado mercados e práticas culturais locais em torno de suas produções musicais, elas acabam servindo como base distintiva para a projeção de músicos locais para além das fronteiras regionais, ou de modo agregado, para a conjunção de territórios geográficos e experiências afetivas ao redor de suas produções musicais.

0 trecho abaixo mostra como o jornalista Leonardo Lichote, ao descrever a nova cena musical de MPB, faz uma conexão entre sua emergência e a tessitura cultural da cidade de São Paulo, afirmando que as novas tecnologias (e a circulação de bens culturais na internet) não significam, necessariamente, um arrefecimento do papel da urbe como espaço privilegiado da produção e do consumo de música.

Aos poucos, nos últimos anos, uma geração de artistas baseados em São Paulo, de diferentes motivações e origens (Paraná, Recife, Ceará, Rio e mesmo a capital paulista), vem trocando ideias, e-mails, arquivos MP3, mensagens no Facebook, links do MySpace - produzindo muito e alimentando uma cena que agora, madura, se configura como a mais consistente do país, apesar do pequeno alcance comercial. Pode ser cedo para afirmar, mas talvez pela primeira vez desde a década de 60 , quando foram realizados os festivais e os programas da paulista TV Record (como 'Jovem Guarda' e '0 fino da bossa'), São Paulo concentre os olhares de quem está interessado nos rumos da futura MPB - antes, desde os tempos da Rádio Nacional, passando pela bossa nova e pelo Rock Brasil dos anos 80, o epicentro era 0 Rio (LICHOTE, 2010, grifo nosso).

Assim, pode-se afirmar que no intricado circuito cultural em que as cenas musicais ganham corpo há a projeção de um mapa virtual que possibilita a construção de "territórios sonoros". 
Esses territórios são balizados por processos de midiatização e pelo modo como, os gêneros musicais emergem nos circuitos culturais materializados em diferentes tecidos urbanos através de seus aspectos estéticos, econômicos e sociais.

\section{Gêneros musicais, experiência e cenas}

Uma rápida olhada pelas taxonomias nos

sites de escuta musical, pelos programas de downloads, pelas críticas musicais, pelos sites de relacionamento, pela programação das rádios e TVs tradicionais e por blogs dedicados à música permite perceber que os processos de produção, consumo e circulação da música popular massiva continuam, em parte, conectados aos modos como os rótulos permitem aos atores do universo musical endereçar, consumir, filtrar e reconhecerse através dessas rotulações. De acordo com Felipe Trotta (2011, p. 63):

Na música popular, as classificações dos gêneros musicais são feitas observando-se determinados estilos de voz, combinações de instrumentos, levadas, acompanhamentos, temáticas de letras, relação melodia-letra-harmonia, clichês, e mais uma grande diversidade de fatores que colaboram para a caracterização de um determinado gênero musical. Dentre todos esses elementos, podemos afirmar que dois aspectos são facilmente identificáveis na classificação de um gênero: a sonoridade e o ritmo.

Boa parte das definições de sonoridade destaca seus aspectos imanentes, ou seja, "a sonoridade é o resultado de combinações instrumentais (e eventualmente vocais) que, por sua recorrência em uma determinada prática musical, se transforma em um elemento identificador" (TROTTA, 2011, p. 63).

Uma cena heavy metal, por exemplo, certamente é reconhecida por sonoridades de um gênero que apresenta características estilísticas específicas em qualquer lugar do planeta, mas, ao mesmo tempo, essas mesmas características são negociadas e se transformam em diferenças sonoras e valores sociais que se conformam de acordo com as singularidades dos territórios sonoros em que circulam. Assim, se o outro de uma cena metal em Salvador é a música axé, em uma cidade como Porto Alegre essa circulação sonora negociará com outras expressões musicais. Isso demonstra que os conteúdos das experiências sonoras (o som que é escutado) está atrelado não só aos gêneros em sentido estrito bem como aos lugares e suas delimitações acústicas. Daí a relevância da compreensão de cenas como "territórios sonoros".

Os gêneros não são somente sonoridades, eles envolvem aspectos ideológicos, redes sociais, práticas comerciais e experiências que possuem como centro nevrálgico as expressões musicais. Antes de funcionar como uma camisa de força ou uma etiqueta de gaveta, os gêneros musicais, tal como a cultura em sentido amplo, são locais de disputas, tensões e negociações que envolvem processos de comunicação dinâmicos.

Nesse sentido, os gêneros musicais envolvem regras econômicas (direcionamentos e embalagens), 
regras semióticas (estratégias de produção de sentido inscritas nos produtos musicais) regras estéticas (possibilidades de experiências atreladas a certas sonoridades) e regras técnico-formais (que envolvem a produção, a circulação e a recepção musical em sentido estrito).

Traçar as relações entre gêneros e cenas musicais envolve então localizar práticas sonoras (o que se ouve e em que lugar), práticas de execução/audição (regras formais e ritualizações partilhadas por músicos e audiência, envolvendo tanto produtos quanto competências usuárias), práticas de mercado (como a música popular massiva circula e é embalada nos tecidos urbanos), práticas de sociabilidade (quais valores e gostos são "incorporados" e "excorporados" em determinadas expressões musicais) e práticas estéticas (como experiências sensíveis atreladas ao consumo de música circulam e se materializam na urbe). A concepção fluida de cena possibilita notar que os gêneros musicais antes de serem simples rótulos são modos de tentar nomear experiências sonoras em seus aspectos econômicos, sociais e estéticos.

\section{Sonoridade pesada}

A fim de corporificar as discussões efetivadas até este ponto vamos observar o heavy metal desde seus aspectos genéricos até sua configuração singularizada na canção War for Territory da banda brasileria Sepultura e as possíveis articulações de sua sonoridade com as cenas musicais.

Talvez o heavy metal seja um dos mais codificados dos gêneros musicais surgidos após 0 aparecimento do rock, de acordo com Robert Walser (1993, p. 42, tradução nossa),

Deste modo, a distorção funciona como signo de extremo poder e intensa expressão que transborda de seus canais e materializa um esforço excepcional para produzi-la. Isso não quer dizer que a distorção funciona sempre e em qualquer lugar desse modo; distorção de guitarra tornou-se um signo convencional que é aberto a transformações e múltiplos sentidos. A distorção heavy metal é ligada semioticamente com outras experiências de distorção, mas é somente em um momento histórico particular que a distorção começou a ser percebida em termos de poder ao invés de falha, transgressão intencional ao invés de sobrecarga acidental como música ao invés de barulho. ${ }^{9}$

Reforçando a amplificação da guitarra, os músicos abusam do power chord, técnica de construção de acordes herdada do blues. Esse é um elemento marcante da expressão sonora do metal, pois possibilita a ampliação dos efeitos sonoros da distorção. A técnica consiste em uma simplificação dos acordes que se travestem

"Thus, distortion functions as a sign of extreme power and intense expression by overflowing its channels and materializing the exceptional effort that produces it. This is not to say that distortion always and everywhere functions this way; guitar distortion has become a conventional sign that is open to transformation and multiple meanings. Heavy Metal distortion is linked semiotically with other experiences of distortion, but it is only a particular historical moment that distortion begins to be perceived in terms of power rather than failure, intentional transgression rather than accidental overload - as music rather than noise." 
então em duas notas, a tônica e a quinta, o que permite aumentar a saturação sem dissonâncias, abrindo mão da terça nota da escala. Apesar de ser um elemento simplificador da prática musical, pois elimina a complexidade das notas maiores e menores, a sensação sonora é de preenchimento, de intensidade sonora, sendo um dos fatores responsáveis pela ideia de peso no heavy metal, que, no caso dos shows, depende da qualidade da amplificação, dos captadores e dos sistemas de reprodução de música ao vivo,

0 heavy metal fundamenta-se profundamente nos efeitos da tecnologia, não menos importante para a pureza de seu volume de som, impossível até algumas décadas atrás. Mas o reverb e as unidades de eco, bem como as sofisticadas técnicas de overdubbing tornaram-se importantes para as gravações e performances de metal. Esse processo expandiu o espaço aural, fazendo parecer que o poder da música se estende indefinidamente. Essa espacialidade complementa a intensa fisicalidade do que é comumente chamado heavy metal, uma materialidade paradoxalmente criada pelo som, mas um som tão alto e convincente quefundem as realidade externas e internas da audiência ${ }^{10}$ (WALSER, 1993, p. 45, tradução nossa).

Outro fator musical que se sobressai nas canções de metal é o riff, uma seqüência significante de notas, geralmente executada pela guitarra e que funciona como marcador da amplitude e da reiteração sonora do heavy metal. ${ }^{11} \mathrm{~A}$ intensidade do volume não está relacionada somente a altura, mas também a qualidade sensível dessa intensidade e a utilização de técnicas musicais específicas, ou seja, mesmo para a sonoridade heavy metal um som alto e mau misturado será considerado um som ruim.

Aos mais desavisados pode parecer que os vocais de boa parte das canções de metal sejam gritados, mas na verdade eles obedecem a técnicas específicas do gênero, como o vocal gutural, uma tipo de canto que produz sonoridades graves através da respiração e de distorções produzidas no aparelho fonador e é responsável pela sensação de agressividade nas vozes do metal contemporâneo. 0 que realmente parece incomodar aos ouvidos "não-iniciados" no gênero é o fato de que nas gravações o vocal é, na maioria dos casos, mixado no mesmo volume dos outros instrumentos, ou seja, importa mais sua sonoridade do que o entendimento exato do que está sendo cantado. 0 vocal, neste caso, também tem a função de fazer vibrar os corpos dos ouvintes como acontece com a distorção das guitarras. Há uma tendência de prolongamento

"Heavy metal relies heavily on technology for its effects, not least for this sheer volume of sound, impossible until recent decades. But reverb and echo units, as well as sophisticated overdubbing techniques, have also become important to metal performance and recording. Such processing can expand aura space, making the music's power seem to extend infinitely. This spatiality complements the intense physicality of what is aptly called "heavy metal", a materiality paradoxically created by sound, but sound so loud and compelling as to conflate inner and outer realities for the audience."

São exemplos característicos de riffs as aberturas de canções tradicionais do gênero como Smoke on The Water e Paranoid, respectivamente das bandas inglesas pioneiras de heavy metal Deep Purple e Black Sabbath. 
no final das frases para corroborar a sensação

de preenchimento do espaço sonoro e de vocalizar certas palavras de modo diferenciado, possibilitando o entendimento do significado das palavras cantadas.

0 heavy metal também acentua, em boa parte dos casos, 0 refrão ${ }^{12}$ como se fosse um grito de ordem, já que quando funciona de maneira homônima ao título da canção ele acaba sendo de fácil entendimento, corroborando a sensação de preenchimento coletivo do espaço de propagação do som..$^{13}$ Pode-se notar então, que antes de ser produzido a partir da intensidade do grave, a sensação sonora de peso está conectada a amplitude do espectro sonoro e intensidade de preenchimento desse espaço. Isso se desdobra em elementos não-sonoros, mas que intensificam essa sensação, como a utilização de temáticas sombrias, cores escuras, ritmação corporal com as cabeças e semblantes sérios.

Usualmente, 0 ritmo no heavy metal funciona como uma pulsação marcada continuamente pelo contrabaixo e pela bateria. A execução desses instrumentos também podem apresentar traços de virtuosidade, mas em geral isso acontece como uma dinâmica entre continuidade da pulsação e liberdade de execução dos instrumentos. ${ }^{14}$

\begin{abstract}
Acentos e desvios rítmicos, sejam performatizados pelo vocalista, pelo guitarrista ou por toda a banda são mais significativos por serem tocados contra o sólido pulso que caracteriza o metal. Embora boa parte do metal seja no tempo 4/4, 0 quadro ritmico é organizado mais como um pulso do que como uma métrica ${ }^{15}$ (WALSER, 1993, p. 49, tradução nossa).
\end{abstract}

A força da cozinha no heavy metal, contrabaixo e bateria, também é associada a capacidade de projeções espaciais obtidas pela microfonagem e amplificação desses instrumentos. Antes do processo de trigagem da bateria ${ }^{16}$ era comum as baterias das grandes bandas serem gravadas em espaços amplos para infundir no ouvinte a sensação de profundidade e preenchimento sonoro.

Os timbres do contrabaixo são pesados quando dão a impressão aurática de grandes dimensões. Também os sons das guitarras, dos bum-

Refrão ou estribilho é, em geral, a parte vocal de fácil assimilação e que é repetida várias vezes ao longo da canção.

13 É muito comum a utilização do refrão como um grito coletivo que acentua a catarse em um show de metal. Entre os inúmeros exemplos de canção que exploram essa estratégia podemos citar Run To the Hills da banda inglesa Iron Maiden e Seek and Destroy da banda norte-americana Metallica.

14 Como já demonstrou Walser (1993) as características sonoras e ideológicas do heavy metal acentuam, na maioria dos casos, os traços de masculinidade associados ao gênero musical.

15 "Accents and rhythmic deviations, whether performed by the vocalist, the guitar soloist, or the whole band, are allthe more significant for being played against the solid pulse that characterizes metal. Although most metal is in $4 / 4$ time, the rhythmic framework is organized more basically around a pulse than a meter." 
bos e de toda a equalização de uma gravação são pesados quando as frequências altas e baixas são enfatizadas; mais do que uma expansão harmônica, a ênfase nas frequências baixas empresta aos instrumentos força e pegada tátil enquanto o pedal de distorção intensifica os harmônicos dando as partes individuais definição e prevenindo a mixagem de ficar suja ${ }^{17}$ (BERGER, 1999, p. 58, tradução nossa).

Como todo gênero caracterizado pela escuta dedicada, ${ }^{18} 0$ heavy metal também possui suas genealogias, o que pressupõe conhecimento dos músicos fundadores, de suas biografias e da árvore genealógica dos subgêneros do metal. É comum nessas narrativas envolver em uma mesma tessitura sonoridades, aspectos sociológicos e comerciais em torno da noção de autenticidade. Ao reconstruir a trajetória da banda inglesa Led Zeppelin, considerada um dos grupos fundadores do gênero, o crítico Mikail Gilmore (2010, p. 343) destaca a importância da sonoridade para a poética da banda: "[...] o que mais incomodava os críticos em relação ao Led Zeppelin era o som: 0 trovão da bateria de John Bonham, a voz aguda e lasciva de Robert Plant, os ensurdecedores solos de guitarra de Jimmy
Page - tudo isso era visto como manifestação de fúria e ofensa".

Outro ponto que pode-se se destacar é que essas tessituras genealógicas não são estanques, para os fãs mais jovens o que estou chamando em termos amplos de heavy metal é o que se designa hoje como metal, enquanto heavy metal seria a denominação específica para a sonoridade afirmada nos anos 1980 e oriunda principalmente das bandas da chamada "New Wave of Britsh Heavy Metal". Acredito que longe de intrigas ou disputas menores, essas realocações dos rótulos são marcos geracionais e identitárias (noção de si) que atravessam diferentes agenciamentos de experiências que podem acionar, ao mesmo tempo, o comum e 0 diverso, em torno de uma mesma origem musical.

\section{War for teritory}

A faixa Territory, lançada no álbum Chaos A.D ${ }^{19}$ em 1993 pela gravadora Roadrunner, é um cartão de visitas para o metal da banda mineira Sepultura. Apesar dos aspectos globais

Processamento eletrônico do som da bateria acústica através de sensors (triggers) que produzem um sinal elétrico a partir da batidas que permite sintetizar esses sons. Assim, pode-se simular o som de uma gravação da bateria do Led Zeppelin nas gravações atuais.

17 "Bass guitar timbres are heavy when they give the aural impression of great size. Like guitar sounds, bass drum sounds and the overall equalization of a recording are heavy when the extreme low and high-end frequencies are emphasized; more than mere harmonic expansion, the emphasis on lower frequencies provides the instruments with their power and tactile punch, while the boosted upper harmonies give the individual parts definitions and prevent the mix form becoming muddy."

18 Escuta dedicada significa ouvir música com atenção voltada para essa atividade, o que inclui conhecimento das escolas e práticas que caracterizam historicamente um gênero musical. 
do gênero, a canção busca ser singular não só pela sonoridade metal do Sepultura como pelo flerte com sonoridades brasileiras na pulsação percussiva. Dentre as inúmeras escolhas possíveis como material analítico, Territory foi escolhida por ser uma canção emblemática do gênero e por materializar, ao mesmo tempo, as discussões sobre os processos de desterritorialização, territorialização e reterritorialização que caracterizam parte das cenas musicais atuais.

A produção da faixa Territory ficou a cargo de Andy Wallace, que além de discos de metal já produziu trabalhos de astros do rock como Paul McCartney. Em termos sonoros, apesar da característica mixagem heavy metal que coloca instrumentos e vozes quase na mesma altura, a gravação permite distinguir com precisão vozes e instrumentos. Territory associa elementos estéticos a práticas mercadológicas, já que a singularidade da canção é ao mesmo tempo afirmação identitária e posicionamento diferencial no mercado.

0 videoclipe oficial ${ }^{20}$ foi gravado no Oriente Médio com cenas em Jerusalém, no Mar Morto e no deserto. A letra não faz referência direta ao conflito árabe-israelense mas as imagens remetem a essa disputa funcionando como uma espécie de ancoragem para os sentidos da agressividade sonora presentes no som e na letra. Na verdade, os sentidos da letra de Territory ${ }^{21}$ são abertos e permitem inferir que a "disputa por território" vai ser preenchida por significados acoplados pelos ouvintes em diferentes territórios sonoros. A primeira audição dá destaque a força que o refrão ocupa na interação com o ouvinte, reforçando uma das características proeminentes do heavy metal.

A introdução na bateria apresenta um preenchimento sonoro que vai se desdobrar ao longo da canção com a marcação contínua dos tempos fortes. A entrada dos outros instrumentos reforça a intensidade com que o espaço sonoro é construído. As variações de andamento funcionam como ganchos para a participação corporal do ouvinte nas marcações rítmicas. Ao longo da música, os instrumentos harmônicos vão se valer de duas características básicas das canções heavy metal: 1) a utilização do riff, sequências

19 Chaos A.D. é o quinto álbum do Sepultura. De acordo com o site http://www.heavymetalcenter.net, o disco vendeu mais de um milhão de cópias em todo o mundo e rendeu à banda o status de grupo de primeira linha do heavy metal mundial. 0 disco foi gravado pela formação que deu fama internacional à banda, os irmãos Cavalera, Igor-bateria e Max-guitarra e voz, Andreas Kisser na guitarra e Paulo Jr. no contrabaixo.

Disponível em: <http://www.youtube.com/watch?v=Q_WHGV5bejk>

21 Unknown man/ Speaks to the world/Sucking your trust/A trap in every world $>$ (refrão) War for territory $>$ Choice control/Behind propaganda/Poor information/To manage your anger>refrão>Dictators' speech/Bashing off your life/Rule to kill the urge/Dumb assholes speech/Years of fighting/Teaching my son/To believe in that man/Racist human being/Racist ground will live/Shame and regret/Of the pride/You've once possessed>refrão> 
de notas marcantes repetidas principalmente pelas guitarras; 2) a reiteração do Power chord como estratégia para criar a intensidade sonora responsável pela sensação de peso associada ao gênero. Com isso, se produz a sensação de uma intensidade física cadenciada que é reforçada pela repetição do refrão que incita a uma disputa por demarcação territorial.

A partir dessa breve descrição da sonoridade da canção Territory pode-se inferir que esse "território sonoro" é configurado através de uma tensão constante que marca as afirmações de autenticidade do gênero heavy metal. A ideia de território é sensibilizada através de uma articulação dos traços genéricos presentes na canção e suas apropriações em diferentes cenas de heavy metal espalhadas pelo mundo. Essa valorização do autêntico VS cooptado é reiterada pela letra que denuncia alienação e doutrinamento político como formas de cooptação ideológicas. A veemência com que Max Cavalera canta a música corrobora a intensidade sonora como afirmação do gênero musical e do corpo masculino, que se afirma como tensão e potência através da intensidade dos movimentos marcados e agressivos tanto da performance sonora bem como visual da canção Territory. ${ }^{22}$

Levando-se em consideração a cena metal de Belo Horizonte, lugar de origem do grupo Sepultura, é possível imaginar uma gradação em que a afirmação do território sonoro é construída através de negociações entre aspectos globais (gênero heavy metal) e locais (cenas musicais), ou seja, a contraposição heavy metal VS pop desdobra-se em distorção VS sonoridades como a do Clube da Esquina ${ }^{23}$ e imaginário metal VS moral católica. Esses elementos, já discutidos no documentário Ruído das Minas $^{24}$ explicações para que Belo Horizonte tenha se transformado na "capital brasileira do metal", permitem aos fãs transitar entre a projeção virtual de um espaço sonoro, o heavy metal, e as tensões regionalizadas que marcam as apropriações localizadas do gênero.

A projeção sonora de uma disputa por território está conectada a uma sobreposição de experiências em torno da música (a cena metal, 0 gênero e a afirmação de cenas locais). Essa articulação possibilita que músicos e ouvintes se

Para uma análise das contradições identitárias de gênero presentes no heavy metal ver.Janotti Júnior (2013).

Clube da Esquina foi um grupo de músicos mineiros (que lançou um álbum homônimo em 1972) que misturava jazz, música popular brasileira e rock. Entre os participantes destacaram-se Milton Nascimento, Lô Borges e Beto Guedes. 0 grupo marcou de forma hegemônica a ideia de identidade musical mineira associada desde então a músicas que misturam complexidade harmônica, execução precisa e uma certa "suavidade" musical.

240 documentário Ruído das Minas, de Felipe Sartoretto, Gacielle Fonseca e Rafael Sette Cãmara, apresenta a cidade de Belo Horizonte como o berço do heavy metal em solo brasileiro, destacando-se entre suas características sua oposição à sonoridade do Clube da Esquina e às ideias do catolicismo mineiro. 
posicionem como guerrilheiros nas querelas por territórios sonoros e existenciais.

As cenas musicais funcionam assim como um enquadramento de práticas de escuta que englobam experiências estéticas, redes sociais e lógicas econômicas. Os territórios sonoros forjados nas cenas são circunscrições de experiências e consumos culturais, reforçando desse modo a importância dos mapas sonoros para a apreensão do valor estético e econômico da música popular massiva, bem como para a inter-relação entre experiências que articulam aspectos globais e locais das identidades cambiantes que parecem permitir habitar e desabitar a cultura contemporânea.

\section{Referências}

ANTUNES, A. Doçura psicodélica. Rolling Stone, São Paulo, n. 31, p. 26, abr. 2009.

BENNET, A.; PETERSON, R. A. Music scenes: local, translocal, and virtual. Nashville, Vanderbilt University Press. 2004.

BERGER, H. Metal, rock and jazz: perception and the phenomenology of musical experience. Hanover: Wesleyan University Press, 1999.

BRAGA, J. L. A sociedade enfrenta sua mídia: dispositivos sociais de crítica midiática. São Paulo: Paulus, 2006.

COSTA, M. Entrevista Wado. Disponível em < http:// www.screamyell.com.br/>. Acesso em: 01 jan. 2012.

FABBRI, F. Tipos, categorias, gêneros musicales.

Hace falta uma teoria? In: INTERNATIONAL ASSOCIATION FOR THE STUDY OF POPULAR MUSIC. Havana, 2006. Conferência de abertura. Disponível em
< http://www.francofabbri.net/files/Testi_per_Studenti/ TiposCategoriasGeneros.pdf>. Acesso em: 01 nov. 2011.

FRITH, S. Performing Rites: on the value of popular music. Cambridge: Harvard University Press, 1996.

GILMORE, M. Ponto final: crônicas sobre os anos 1960 e suas desilusões. São Paulo: Companhia das Letras, 2010.

GUIMARÃES, C.; LEAL, B. Experiência mediada e experiência estética. In: ENCONTRO ANUAL DA COMPÓS, 16., 2007. Curitiba. Anais... Curitiba: Universidade Tuiuti do Paraná, 2007. Disponível em < http://www.compos.org. br/data/biblioteca_236.pdf > Acesso em: 01 ago. 2010.

HERSCHMANN, M. Indústria da música em transição. São Paulo: Estação das Cores, 2010.

HERSCHMANN, M. Lapa, cidade da música. Desafios e perspectivas para o crescimento do Rio de Janeiro e da indústria da música independente nacional. Rio de Janeiro: Mauad X, 2007.

JANOTTI JÚNIOR, J. Rock With The Devil: notas sobre gêneros e cenas musicais a partir da performatização do feminino IN:In JANOTTI JÚNIOR, J.; SÁ, S. P. (Org.). Cenas Musicais. São Paulo: Anadarco, 2013.

LICHOTE, L. Cena musical contemporânea de São

Paulo se fortalece e é alvo de documentário. 2010. Disponível em: < http://oglobo.globo.com/cultura/ mat/2010/08/07/cena-musical-contemporanea-de-saopaulo-se-fortalece-e-alvo-de-documentario-917345591. asp >. Acesso em: 22 dez. 2010.

MIÉGE, B. A sociedade tecida pela comunicação: técnicas da informação e da comunicação entre inovação e enraizamento social. São Paulo: Paulus, 2009.

SÁ, S. M. A. P. de (Org.). Rumos da cultura da música: negócios, estéticas, linguagens e audibilidades. Porto Alegre: Sulina, 2010.

STRAW, W. Systems of Articulation, Logics of change: Scenes and Communication in Popular Music. Cultural Studies, v. 5, n. 3, Oct. 1991. 
TROTTA, F. 0 samba e suas fronteiras: pagode

romântico" e "samba de raiz" nos anos 1990. Rio de

Janeiro: Editora da UFRJ, 2011.

WALSER, R. Running with the Devil: power, gender,

and madness in heavy metal music. Hanover: Wesleyan

University Press, 1993. 
War for Territory: musical scenes, aesthetics experience and a heavy metal song

\section{War for Territory: escenas musicales, experiencia estética y una canción heavy metal}

\section{Abstract}

This paper addresses musical scenes as sonic territories, where musical genres are materialized, taking as a case study the configuration of heavy metal in its generic traits and how these marks are worked in "Territory", a particular song from the brazilian metal group Sepultura. This analytical exercise allows us to observe the extent to which sound acts as a starting point to articulate aesthetic experiences that permeate local and global aspects of the musical scenes.

\section{Keywords}

Musical Scene. Aesthetic Experience. Heavy Metal.

\section{Resumen}

Este artículo presenta las escenas musicales como territorios sonoros donde se materializan los géneros musicales, tomando como caso de estudio la configuración del heavy metal en sus características genéricas y de qué manera estas etiquetas surgen en la canción Territory de la banda Sepultura. Este ejercicio de análisis nos permite observar el grado en el cual la sonoridad actúa como punto de partida para la articulación de las experiencias estéticas que impregnan las configuraciones local y global de las escenas musicales. Tradução fiel ao original.

\section{Palabras-Clave}

Escenas Musicales. Experiencia estética. Heavy Metal. 


\section{Expediente}

A revista E-Compós é a publicação científica em formato eletrônico da Associação Nacional dos Programas de Pós-Graduação em Comunicação (Compós). Lançada em 2004, tem como principal finalidade difundir a produção acadêmica de pesquisadores da área de Comunicação, inseridos em instituições do Brasil e do exterior.

\section{E-COMPÓS I www.e-compos.org.br I E-ISSN 1808-2599}

Revista da Associação Nacional dos Programas

de Pós-Graduação em Comunicacão.

Brasília, v.17, n.2, mai./ago. 2014.

A identificação das edições, a partir de 2008

passa a ser volume anual com três números.

\section{CONSELHO EDITORIAL}

Afonso Albuquerque, Universidade Federal Fluminense, Brasil Alberto Carlos Augusto Klein, Universidade Estadual de Londrina, Brasil Alex Fernando Teixeira Primo, Universidade Federal do Rio Grande do Sul, Brasil Rio Grande do Sul, Brasi

Ana Gruszynski, Universidade Federal do Rio Grande do Sul, Brasil Ana Silvia Lopes Davi Médola, Universidade Estadual Paulista, Brasil André Luiz Martins Lemos, Universidade Federal da Bahia, Brasi Ângela Freire Prysthon, Universidade Federal de Pernambuco, Brasil Antônio Fausto Neto, Universidade do Vale do Rio dos Sinos, Brasil Antonio Carlos Hohlfeldt, Pontifícia Universidade Católica do Rio Grande do Sul, Brasil Antonio Roberto Chiachiri Filho, Faculdade Cásper Líbero, Brasi Arlindo Ribeiro Machado, Universidade de São Paulo, Brasil Arthur Autran Franco de Sá Neto, Universidade Federal de São Carlos, Brasil Benjamim Picado, Universidade Federal Fluminense, Brasil César Geraldo Guimarães, Universidade Federal de Minas Gerais, Brasil Cristiane Freitas Gutfreind, Pontifícia Universidade Católica do Rio Grande do Sul, Brasil Denilson Lopes, Universidade Federal do Rio de Janeiro, Brasil Denize Correa Araujo, Universidade Tuiuti do Paraná, Brasi Edilson Cazeloto, Universidade Paulista , Brasil

Eduardo Vicente, Universidade de São Paulo, Brasil Eneus Trindade, Universidade de São Paulo, Brasil Erick Felinto de Oliveira, Universidade do Estado do Rio de Janeiro, Brasil Florence Dravet, Universidade Católica de Brasília, Brasil Gelson Santana, Universidade Anhembi/Morumbi, Brasi Gilson Vieira Monteiro, Universidade Federal do Amazonas, Brasil Gislene da Silva, Universidade Federal de Santa Catarina, Brasil Guillermo Orozco Gómez, Universidad de Guadalajara Gustavo Daudt Fischer, Universidade do Vale do Rio dos Sinos, Brasil Hector Ospina, Universidad de Manizales, Colômbia Herom Vargas, Universidade Municipal de São Caetano do Sul, Brasil Ieda Tucherman, Universidade Federal do Rio de Janeiro, Brasil Inês Vitorino, Universidade Federal do Ceará, Brasil Janice Caiafa, Universidade Federal do Rio de Janeiro, Brasil Jay David Bolter, Georgia Institute of Technology Jeder Silveira Janotti Junior, Universidade Federal de Pernambuco, Brasi João Freire Filho, Universidade Federal do Rio de Janeiro, Brasil John DH Downing, University of Texas at Austin, Estados Unidos Ana Carolina Damboriarena Escosteguy, Pontifícia Universidade Católica do

José Afonso da Silva Junior, Universidade Federal de Pernambuco, Brasil José Carlos Rodrigues, Pontifícia Universidade Católica do Rio de Janeiro, Brasil José Luiz Aidar Prado, Pontifícia Universidade Católica de São Paulo, Brasil José Luiz Warren Jardim Gomes Braga, Universidade do Vale do Rio dos Sinos, Brasil Juremir Machado da Silva, Pontifícia Universidade Católica do Rio Grande do Sul, Brasil Laan Mendes Barros, Universidade Metodista de São Paulo, Brasil Lance Strate, Fordham University, USA, Estados Unidos Lorraine Leu, University of Bristol, Grã-Bretanha Lucia Leão, Pontifícia Universidade Católica de São Paulo, Brasil Luciana Panke, Universidade Federal do Paraná, Brasil Luiz Claudio Martino, Universidade de Brasília, Brasil Malena Segura Contrera, Universidade Paulista, Brasil Márcio de Vasconcellos Serelle, Pontifícia Universidade Católica de Minas Gerais, Brasil Maria Aparecida Baccega, Universidade de São Paulo e Escola Superior de Propaganda e Marketing, Brasil Maria das Graças Pinto Coelho, Universidade Federal do Rio Grande do Norte, Brasil Maria Immacolata Vassallo de Lopes, Universidade de São Paulo, Brasil Maria Luiza Martins de Mendonça, Universidade Federal de Goiás, Brasil Mauro de Souza Ventura, Universidade Estadual Paulista, Brasil Mauro Pereira Porto, Tulane University, Estados Unidos Nilda Aparecida Jacks, Universidade Federal do Rio Grande do Sul, Brasil Paulo Roberto Gibaldi Vaz, Universidade Federal do Rio de Janeiro, Brasil Potiguara Mendes Silveira Jr, Universidade Federal de Juiz de Fora, Brasil Renato Cordeiro Gomes, Pontifícia Universidade Católica do Rio de Janeiro, Brasil Robert K Logan, University of Toronto, Canadá

Ronaldo George Helal, Universidade do Estado do Rio de Janeiro, Brasil Rosana de Lima Soares, Universidade de São Paulo, Brasi Rose Melo Rocha, Escola Superior de Propaganda e Marketing, Brasil Rossana Reguillo, Instituto de Estudos Superiores do Ocidente, Mexico Rousiley Celi Moreira Maia, Universidade Federal de Minas Gerais, Brasi Sebastião Carlos de Morais Squirra, Universidade Metodista de São Paulo, Brasil Sebastião Guilherme Albano da Costa, Universidade Federal do Rio Grande do Norte, Brasil

Simone Maria Andrade Pereira de Sá, Universidade Federal Fluminense, Brasi Tiago Quiroga Fausto Neto, Universidade de Brasília, Brasil Suzete Venturelli, Universidade de Brasília, Brasil Valerio Fuenzalida Fernández, Puc-Chile, Chile Veneza Mayora Ronsini, Universidade Federal de Santa Maria, Brasil Vera Regina Veiga França, Universidade Federal de Minas Gerais, Brasil

\section{COMISSÃO EDITORIAL}

Cristiane Freitas Gutfreind I Pontifícia Universidade Católica do Rio Grande do Sul, Brasil Irene Machado I Universidade de São Paulo, Brasil

Jorge Cardoso Filho I Universidade Federal do Reconcavo da Bahia, Brasil / Universidade Federal da Bahia, Brasil

CONSULTORES AD HOC

Adriana Amaral, Universidade do Vale do Rio dos Sinos, Brasil

Alexandre Rocha da Silva, Universidade Federal do Rio Grande do Sul, Brasi Arthur Ituassu, Pontifícia Universidade Católica do Rio de Janeiro, Brasil Bruno Souza Leal, Universidade Federal de Minas Gerais, Brasil Elizabeth Bastos Duarte, Universidade Federal de Santa Maria, Brasil Francisco Paulo Jamil Marques, Universidade Federal do Ceará, Brasi Maurício Lissovsky, Universidade Federal do Rio de Janeiro, Brasil Suzana Kilpp, Universidade do Vale do Rio dos Sinos, Brasil Vander Casaqui, Escola Superior de Propaganda e Marketing, Brasil

EDIÇÃO DE TEXTO E RESUMOS I Susane Barros SECRETÁRIA EXECUTIVA I Helena Stigger EDITORAÇÃo ELETRÔNICA I Roka Estúdio
COMPÓS I www.compos.org.br

Associação Nacional dos Programas de Pós-Graduação em Comunicação

Presidente

Eduardo Morettin

Universidade de São Paulo, Brasil

eduardomorettin@usp.br

Vice-presidente

Inês Vitorino

Universidade Federal do Ceará, Brasil

ines@ufc.br

Secretária-Geral

Gislene da Silva

Universidade Federal de Santa Catarina, Brasil

gislenedasilva@gmail.com 